\title{
The relationship between atopy and allergic contact dermatitis in Israeli patients
}

\author{
Dan Slodownik ${ }^{1,2}$, Sobhia Mruwat Rabah ${ }^{3}$, Assi Levi ${ }^{2,4}$, Shlomo Moshe ${ }^{5,6}$, Moshe Lapidoth ${ }^{2,4}$, Arieh Ingber $^{3}$, \\ Jacob Mashiah ${ }^{1,2}$
}

${ }^{1}$ Department of Dermatology, Tel Aviv Sourasky Medical Center, Tel Aviv, Israel

${ }^{2}$ Sackler School of Medicine, Tel Aviv University, Tel Aviv, Israel

${ }^{3}$ Department of Dermatology, Hadassah-Hebrew University Medical Center, Jerusalem, Israel

${ }^{4}$ Division of Dermatology, Rabin Medical Center, Petah Tikva, Israel

${ }^{5}$ Sackler Faculty of Medicine, School of Public Health, Department of Environmental and Occupational Health, Tel Aviv University, Tel Aviv, Israel

${ }^{6}$ Maccabi Healthcare Services, Jerusalem and Hashfela District, The Occupational Clinic, Holon, Israel

Adv Dermatol Allergol 2022; XXXIX (1): 159-163

DOI: https://doi.org/10.5114/ada.2022.113606

\begin{abstract}
Introduction: Whether individuals with atopic diseases have a different risk of contact allergy compared to those who are non-atopic is controversial and data are conflicting.

Aim: To explore the association between atopy and allergic contact dermatitis (ACD).

Material and methods: This retrospective cross-sectional study included 301 patients referred to a tertiary clinic to evaluate ACD. Demographic details including personal and familial mucosal or cutaneous atopic status were recorded. Patch tests were tailored to their clinical presentations and relevant exposures.

Results: At least 1 positive patch test reaction was observed in 177 patients (59\% of the study cohort), of which $52 \%$ had a history of atopic diseases, compared with $44 \%$ of patients with a negative patch test result $(p=0.2)$. Additionally, 147 patients had an atopic background, of which 92 (62\%) had $\geq 1$ positive patch test result, compared with $55 \%$ of non-atopic patients $(p=0.2)$. Nickel sulphate was the most common contact allergen $(13.4 \%$ of the patch test reactions).

Conclusions: We identified a positive tendency for atopic diseases among individuals with ACD and vice versa. Our study supports the aggregate data from previous studies despite the non-significant differences between the study and control groups. However, further research performed in larger populations of patients is necessary to evaluate the real association between atopy and ACD on a solid basis. Our results indicate the necessity of systematic patch testing in patient setups with atopic background and chronic dermatitis.
\end{abstract}

Key words: atopy, allergic contact dermatitis, allergen, patch testing.

\section{Introduction}

Atopic patients have an inherent tendency to develop allergic reactions to environmental stimuli such as chemical, physical and biological ones. Atopic diseases are classically divided into mucosal atopic diseases that include allergic rhinoconjunctivitis and asthma, and cutaneous atopic disease, e.g. atopic dermatitis (AD). Although a clear association between atopy and increased reactivity to irritants is known [1], the association between atopy and allergic contact dermatitis (ACD) still remains controversial. Individuals with AD may be at a higher risk of contact sensitization due to a defective skin bar- rier caused by the well-replicated filaggrin (FLG) loss-offunction mutation and other mutations such as SPINK5, FLG-2, SPRR3, and CLDN1, leading to increased allergen penetration [2-5]. On the other hand, such patients were considered to be characterized by a clearly dominant Th2 cytokine profile, responsible for attenuated delayed hypersensitivity responses.

\section{Aim}

In this study, we aimed to explore possible association between mucosal and cutaneous atopic diseases and ACD. Although most former studies considered the

Address for correspondence: Dan Slodownik MD, Department of Dermatology, Tel Aviv Sourasky Medical Center, 6 Weitzman St, Tel Aviv 6423906, Israel, e-mail: dans@tlvmc.gov.il Received: 29.05.2020, accepted: 28.11.2020. 
relationship between $A D$ and $A C D$, the literature regarding the whole spectrum of atopic diseases with respect to ACD is relatively sparse.

\section{Material and methods}

This retrospective case-control study included $301 \mathrm{pa}-$ tients, referred to a tertiary referral patch test clinic over a 2-year period. Patients were predominantly referred for the investigation of suspected ACD. Complete medical history was obtained including demographic data, relevant domestic and occupational exposures, personal and family history of $A D$, asthma, and rhinoconjunctivitis. All patients were extensively patch tested with the European baseline as well as individually composed series of contact allergens (Chemotechnique Diagnostics, Vellinge, Sweden). Readings were obtained on day (D) 4 for all patients. The patients were instructed to return on D7 if additional reactions were observed later [6]. Positive reactions were evaluated as weak $(+)$, strong $(++)$, and extreme (+++) according to the International Contact Dermatitis Research Group and European Society of Contact Dermatitis (ESCD) criteria [6]. Clinical relevance was defined according to the ESCD criteria [6].

\section{Statistical analysis}

Univariate analysis was used to determine the correlation between each explanatory variable and study group (atopic vs. non-atopic). Categorical variables were analysed using Pearson's $\chi^{2}$-test or Fisher's exact test and were reported as relative frequencies. A $p$-value of 0.05 was considered significant. Statistical analysis was performed by SAS for Windows version 9.4 (SAS, NC, USA). Ethical approval was obtained from the local committee.

\section{Results}

This study included 301 patients. A hundred forty-seven (49\%) had a personal or family history of atopic diseases. Within the general population study of 301 patients,

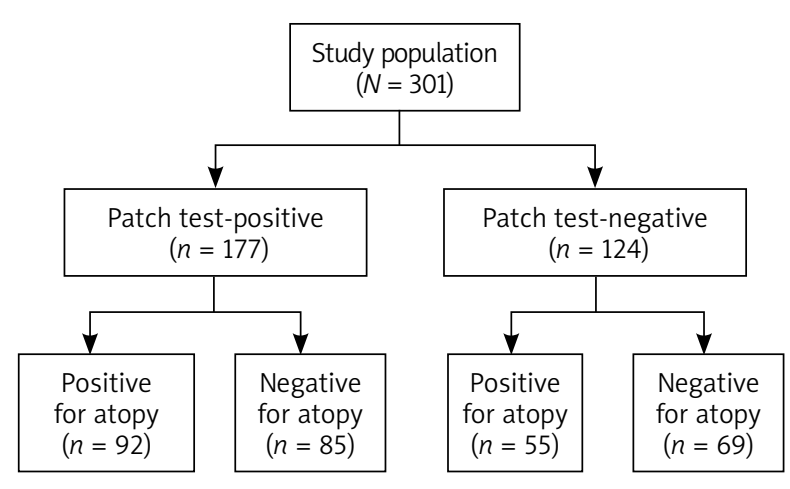

Figure 1. Study population characteristics
177 presented with $\leq 1$ positive patch test reaction (study group A). Non-reacting patients were defined as the control group A (Figure 1). In the study group A, 117 patients (80\% of the atopic group) had only mucosal presentation of atopic allergy. The MOAHLFA index for the investigated populations is shown in Table 1 . Characteristics of the study and control groups A are further described in Table 2. Difference in terms of atopic background between the 2 groups mentioned above was not significant (study group $-52 \%$ and control group $-44 \%, p=0.2$ ).

Occupational characteristics of the study group $A$ and the control group A are described in Table 3. There was a significant difference in occupational distribution $(p<$ 0.03 ) between the groups. The difference was especially observed in the proportion of teaching, housekeeping and health professionals and army personnel among the groups. Localization of dermatitis is described in Table 4. Prevalence of the most common allergens in the study group is summarized in Table 5.

All data were further categorized to study and control groups B according to the atopic background, meaning that the study group B was defined as patients with an atopic background while the control group $B$ had no atopic background. In the population of 147 atopic patients (study group B), 62\% of positive reactions were recorded in comparison to $55 \%$ of those in the control group B (Table 6). However, the difference was not significant $(p=0.2)$. The relevance rate of the positive reactions was $90 \%$ in the study group and was not significantly different from that of the control group (93\%). Localizations of dermatitis and occupational parameters were also not significantly different between the study and control groups $\mathrm{B}$.

\section{Discussion}

Two contradictory mechanisms determine the relationship between atopy and contact sensitization. Early experimental studies found reduced contact sensitization among patients with AD. The simplistic archaic concept theorized that contradictory unmixed Th1/Th2 immune profiles promote either atopic tendency or contact sensitization [7-9]. On a clinical level, a biased referral pattern

Table 1. MOAHLFA index for the investigated populations

\begin{tabular}{lcc}
\hline Parameter & $\boldsymbol{N}$ & $\%$ \\
\hline Men & 124 & 41.3 \\
\hline Occupational dermatitis & 51 & 16.9 \\
\hline Atopic dermatitis & 60 & 19.9 \\
\hline Hand dermatitis & 69 & 22.9 \\
\hline Leg dermatitis & 29 & 9.6 \\
\hline Face dermatitis & 52 & 17.2 \\
\hline Age $>40$ & 119 & 40 \\
\hline
\end{tabular}


of patients with $A D$ for patch testing to exclude contact sensitization in patients with poorly controlled dermatitis may lead to inverse association [10]. As mentioned above, patients with atopic diseases present a genetic induced impaired skin barrier structure and function. This type of defect may potentially increase allergen penetration.

A Polish study performed by Poninska et al. demonstrated that filaggrin mutations increase the risk of ACD development as well as atopic asthma also in the absence of AD [11]. Possible immunological mechanisms for contact sensitization in patients with atopy are increased levels of Th2 cytokines being responsible for promotion of ACD development [12] and elevated antigen presentation and processing components [13]. In addition, patients with $A D$ are more likely to systematically use various skin-care products and therefore significantly increase the risk of skin sensitization to allergenic ingredients [14] of the formulations.

Another possible challenge in determining a possible correlation is a lack of uniformity in defining "atopy". Spiewak [15] reviewed the literature regarding the interplay between atopy and contact dermatitis and found more than 10 different definitions of the term "atopy," some of which interchange terminology of atopy and atopic eczema, making the analysis of results highly difficult.

Past decade publications tend to support a positive correlation between atopy and ACD. Kirchhof identified that patients with a personal or familial history of atopy have an increased risk of ACD [1]. A Danish study demonstrated that contact allergy was more frequent in participants who reported $A D$ in comparison to non-AD patients [16]. Another study in Californian paediatric patients showed a significantly different rate of contact reactivity in $89 \%$ of patients with $A D$, as compared with $66 \%$ rate in non-AD patients [17]. A recent single centre study performed in a population of 46,250 patients examined over a 30-year period, concluded that contact allergy to nickel sulphate, cobalt chloride, and primin was less likely to develop in the group of $A D$, whereas substances found in topical dermatological products were more likely to induce contact allergy in patients with $\mathrm{AD}$ [18]. A slightly different view regarding this issue was addressed by Scott et al.; the authors compared the prevalence of positive results of patch tests to allergens known to be causative for development of systemic contact dermatitis in patients with $A D$ with and without respiratory atopic diseases. Their conclusion was that children and adolescents, although not adults, with $A D$ and respiratory atopy, were more likely to have positive patch tests to allergens with potential to induce systemic contact allergy than age-matched patients with AD without respiratory atopy [19]. A systematic review and meta-analysis [20] of 74 publications from the last 60 years indicated a positive correlation in studies that compared patients with AD with individuals from the general population, but an inverse association when comparing with referred populations.
Table 2. Demographic and atopy data in the study group A and the control group A

\begin{tabular}{lccc}
\hline Variable & $\begin{array}{c}\text { Study } \\
\text { group A } \\
(n=177)\end{array}$ & $\begin{array}{c}\text { Control } \\
\text { group A } \\
(n=124)\end{array}$ & $P$-value \\
\hline Age [years] mean \pm SD & $39.32 \pm 15.48$ & $36.11 \pm 16.91$ & 0.75 \\
\hline Gender, $n(\%):$ & & & \\
\hline Male & $62(35)$ & $62(50)$ & $<0.01$ \\
\hline Female & $115(65)$ & $62(50)$ & $<0.01$ \\
\hline Atopic background, $n(\%)^{\dagger}$ & $92(52)$ & $55(44)$ & 0.2 \\
\hline
\end{tabular}

${ }^{\dagger}$ Atopic background was not significantly different between study and control groups.

Table 3. Occupational distribution among the study group A and the control group $A^{*}$

\begin{tabular}{lccc}
\hline Occupation & $\begin{array}{c}\text { Study } \\
\text { group A } \\
(\%)\end{array}$ & $\begin{array}{c}\text { Control } \\
\text { group A } \\
(\%)\end{array}$ & $\begin{array}{c}\text { Ratio } \\
(\mathbf{A}: \text { : })^{\S}\end{array}$ \\
\hline Administration & 17.51 & 16.93 & 1.034 \\
\hline Laboratory & 3.95 & 3.22 & 1.226 \\
\hline Teaching & 10.73 & 5.64 & 1.92 \\
\hline Service workers & 7.34 & 8.87 & 0.82 \\
\hline Health professionals & 8.47 & 5.64 & 1.50 \\
\hline Building and maintenance & 3.95 & 3.22 & 1.22 \\
\hline Machinery and mechanics & 7.91 & 9.6 & 0.82 \\
\hline Manufacturing & 3.39 & 4.83 & 0.70 \\
\hline Combat soldiers & 7.91 & 25 & 0.3164 \\
\hline Housekeeping & 9.04 & 5.64 & 1.602 \\
\hline Unknown\# & 19.77 & 11.29 & 1.75
\end{tabular}

*Occupation classification is according to the Standard Occupational Classification and Coding Structure, SOC. `Distribution of the occupation among the members of the groups, was significantly different $(p<0.003)$. "Unknown occupation means that no data were found regarding occupation in the patient's file.

Table 4. Dermatitis location among the study group A and the control group A

\begin{tabular}{lccc}
\hline Site & $\begin{array}{c}\text { Study group A } \\
(\%)\end{array}$ & $\begin{array}{c}\text { Control group A } \\
(\%)\end{array}$ & $\begin{array}{c}\text { Ratio } \\
(\mathbf{A}: \mathbf{B})^{\S}\end{array}$ \\
\hline Head and neck & 37.4 & 42.9 & 0.87 \\
\hline Extremities & 17.0 & 17.5 & 0.97 \\
\hline Palms & 23 & 16.5 & 1.39 \\
\hline Torso & 9.1 & 12.7 & 0.71 \\
\hline Soles & 9.5 & 8 & 1.22 \\
\hline Groins & 3.9 & 2.4 & 1.62 \\
\hline
\end{tabular}

${ }^{\S}$ Distribution of the dermatitis location among the members of the groups was not significantly different $(p=0.58$ ).

It is clearly noticeable that the results provided by different researchers are conflicting. The lack of consistency in the definition and terminology of atopy is one of 
Table 5. Prevalence of the most common allergens among the study group

\begin{tabular}{ll}
\hline Allergen & $\begin{array}{c}\text { Percentage (\%) } \\
\text { of tested recruits* }\end{array}$ \\
\hline Nickel sulfate & 13.4 \\
\hline MI & 6.7 \\
\hline Cobalt chloride & 6.4 \\
\hline Fragrance mix I & 5.5 \\
\hline Potassium dichromate & 4.3 \\
\hline Thiomersal & 4.3 \\
\hline Acrylates & 4.3 \\
\hline Colophony & 4.0 \\
\hline Methyldibromo glutaronitrile & 3.9 \\
\hline Myroxylon pereirae & 3.6 \\
\hline Formaldehyde & 3.6 \\
\hline Own products & 3.3 \\
\hline MCl/MI & 3.0 \\
\hline Dodecyl gallate & 2.4 \\
\hline Quaternium 15 & 2.1 \\
\hline$p$-Phenylenediamine & 1.8 \\
\hline Epoxy resin & 1.8 \\
\hline Textile dyes & 1.5 \\
\hline Neomycin & 1.5 \\
\hline Thiuram mix & 1.5 \\
\hline Paraben mix & 1.5 \\
\hline 4-tert-butylphenol formaldehyde resin & 1.2 \\
\hline Cocamidopropyl betaine & 1.2 \\
\hline Sorbitan sesquioleate & 1.2 \\
\hline Benzocaine & 1.2 \\
\hline$* 45 \%$ of the subjects reacted to 1 allergen, the rest reacted to 2 or more al- \\
lergens.
\end{tabular}

Table 6. Demographic and atopy data in the study group B and the control group B

\begin{tabular}{lccc}
\hline Variable & $\begin{array}{c}\text { Study } \\
\text { group B } \\
(n=147)\end{array}$ & $\begin{array}{l}\text { Control } \\
\text { group B } \\
(n=154)\end{array}$ & $P$-value \\
\hline Age [years] mean \pm SD & $36.35 \pm 15.54$ & $39.57 \pm 16.57$ & $<0.09$ \\
\hline Sex, $n(\%):$ & & & \\
\hline Male & $62(43)$ & $62(41)$ & $>0.82$ \\
\hline Female & $85(57)$ & $92(59)$ & \\
\hline Positive patch test, $n(\%)^{\dagger}$ & $92(62.6)$ & $85(55.2)$ & 0.2
\end{tabular}

${ }^{t}$ Prevalence of allergic contact dermatitis was not significantly different between the study and control groups $(p=0.2)$.

the reasons responsible for such variability. Most studies refer almost exclusively to AD. Others use inconsistent criteria for inclusion such as a family history of atopic diseases, but no personal history of AD. Other factors may include lack of uniformity in study designs, the vast number of them being retrospective. Some studies show differences in patch test techniques including differences in the haptens and concentrations used and in the interpretation of patch test reactions and relevance.

Our study is the first report from Israel to evaluate the relation between atopy and ACD. We did not find a significant difference between persons with atopy to nonatopic; however, a positive tendency for atopy among individuals with ACD and vice versa was identified.

Our cohort characteristics align with that of European reports regarding MOAHLFA index [21] except for age. It may reflect a referral bias as our centre is a tertiary referral centre for the army. It may also explain differences of occupational distribution as army personnel tend to have higher rates of irritant contact dermatitis [22]. Moreover, the relatively high atopy rate in our cohort should also be considered, given the referral bias of persons with atopy in patch test clinics and the rising atopy rate in Israel over the past decades $[23,24]$.

\section{Conclusions}

Our study supports a positive tendency of patients with atopy to have ACD, although not significantly. This observation aligns with that of former studies and emphasizes the need for patch testing in patients with atopy with long standing dermatitis.

\section{Conflict of interest}

The authors declare no conflict of interest.

\section{References}

1. Kirchhof MG, de Gannes GC. Atopy associated with positive patch test and possible allergic contact dermatitis. J Cutan Med Surg 2018; 22: 405-10.

2. Gittler JK, Krueger JG, Guttman-Yassky E. Atopic dermatitis results in intrinsic barrier and immune abnormalities: implications for contact dermatitis. J Allergy Clin Immunol 2013; 131: 300-13.

3. Thyssen JP, Linneberg A, Ross-Hansen K, et al. Filaggrin mutations are strongly associated with contact sensitization in individuals with dermatitis. Contact Dermatitis 2013; 68: 273-6.

4. Liang Y, Chang C, Lu Q. The genetics and epigenetics of atopic dermatitis-filaggrin and other polymorphisms. Clin Rev Allergy Immunol 2016; 51: 315-28.

5. Osawa R, Akiyama M, Shimizu H. Filaggrin gene defects and the risk of developing allergic disorders. Allergol Int 2011; 60: 1-9.

6. Johansen JD, Aalto-Korte K, Agner T, etal. European Society of Contact Dermatitis guideline for diagnostic patch testing-recommendations on best practice. Contact Dermatitis 2015; 73 : 195-221.

7. Uehara M, Sawai T. A longitudinal study of contact sensitivity in patients with atopic dermatitis. Arch Dermatol 1989; 125 : 366-8.

8. Forsbeck M, Hovmark A, Skog E. Patch testing, tuberculin testing and sensitization with dinitrochlorobenzene and nitrosodimethylanilini of patients with atopic dermatitis. Acta Derm Venereol 1976; 56: 135-8. 
9. Rees J, Friedmann PS, Matthews JN. Contact sensitivity to dinitrochlorobenzene is impaired in atopic subjects. Controversy revisited. Arch Dermatol 1990; 126: 1173-5.

10. Chen JK, Jacob SE, Nedorost ST, et al. A pragmatic approach to patch testing atopic dermatitis patients: clinical recommendations based on expert consensus opinion. Dermatitis 2016; 27: 186-92.

11. Poninska J, Samolinski B, Tomaszewska A, et al. Filaggrin gene defects are independent risk factors for atopic asthma in a Polish population: a study in ECAP cohort. PLoS One 2011; 6: e16933.

12. Gittler JK, Shemer A, Suarez-Farinas M, et al. Progressive activation of $T(H) 2 / T(H) 22$ cytokines and selective epidermal proteins characterizes acute and chronic atopic dermatitis. J Allergy Clin Immunol 2012; 130: 1344-54.

13. Novak N, Tepel C, Koch S, et al. Evidence for a differential expression of the FcepsilonRIgamma chain in dendritic cells of atopic and nonatopic donors. J Clin Invest 2003; 111: 1047-56.

14. Mailhol C, Lauwers-Cances V, Rance F, et al. Prevalence and risk factors for allergic contact dermatitis to topical treatment in atopic dermatitis: a study in 641 children. Allergy 2009; 64: 801-6.

15. Spiewak R. Contact dermatitis in atopic individuals. Curr Opin Allergy Clin Immunol 2012; 12: 491-7.

16. Thyssen JP, Linneberg A, Engkilde K, et al. Contact sensitization to common haptens is associated with atopic dermatitis: new insight. Br J Dermatol 2012; 166: 1255-62.

17. Herro EM, Matiz C, Sullivan K, et al. Frequency of contact allergens in pediatric patients with atopic dermatitis. J Clin Aesthet Dermatol 2011; 4: 39-41.

18. Teo Y, McFadden JP, White IR, et al. Allergic contact dermatitis in atopic individuals: results of a 30-year retrospective study. Contact Dermatitis 2019; 81: 409-16.

19. Scott JF, Conic RRZ, Kim I. Atopy and sensitization to allergens known to cause systemic contact dermatitis. Dermatitis 2019; 30: 62-6.

20. Hamann CR, Hamann D, Egeberg A, et al. Association between atopic dermatitis and contact sensitization: a systematic review and meta-analysis. J Am Acad Dermatol 2017; 77: 70-8.

21. Uter W, Geffeler O, Gimenez-Arnau A, et al. Characteristics of patients patch tested in the European Surveillance System on Contact Allergies (ESSCA) network, 2009-2012. Contact Dermatitis 2015; 73: 82-90.

22. Slodownik D, Reiss A, Mashiach Y, et al. Textile and shoe allergic contact dermatitis in military personnel. Dermatitis 2018; 29: 196-9.

23. Shreberk-Hassidim R, Hassidim A, Gronovich Y, et al. Atopic dermatitis in Israeli adolescents from 1998 to 2013: trends in time and association with migraine. Pediatr Dermatol 2017; 34: 247-52.

24. Wohl Y, Wainstein J, Bar-Dayan Y. Atopic dermatitis in Israeli adolescents - a large retrospective cohort study. Acta Derm Venereol 2014; 94: 695-8. 